\title{
IMPLEMENTASI PROGRAM BANTUAN SOSIAL PEMUGARAN RUMAH TIDAK LAYAK HUNI (RTLH) DI DESA NGOTET KAB. REMBANG TAHUN 2017
}

\author{
Natalia Kusuma Dewi ${ }^{1}$, Melly Anggraeni ${ }^{2}$, Ida Hayu Dwimawanti ${ }^{3}$
}

\begin{abstract}
Abstrak
Kemiskinan diartikan sebagai kondisi ketidakmampuan pendapatan dalam mencukupi kebutuhan pokok sehingga kurang mampu untuk menjamin kelangsungan hidup (Suryawati, 2004: 122). Menurut Badan Pusat Statistik Republik Indonesia, Provinsi Jawa Tengah menempati posisi dua puluh satu dari tiga puluh empat provinsi dengan jumlah penduduk miskin sebesar 3,90 juta penduduk atau sebesar 11,32\%. Dengan kondisi tersebut, saat ini terdapat lima belas kabupaten di wilayah Provinsi Jawa Tengah yang berada di bawah garis kemiskinan (Zona Merah) salah satunya adalah Kabupaten Rembang dengan jumlah penduduk miskin pada tahun 2017 sebesar 115,19 ribu atau sebesar 18,35\% dari seluruh jumlah penduduk. Tingginya persentase penduduk miskin yang ada di Kabupaten Rembang tersebut mencerminkan masih banyaknya rumah penduduk yang masuk dalam kategori tidak layak huni. Oleh sebab itu, Pemerintah Kabupaten Rembang pada tahun 2017 mulai melaksanakan Program Bantuan Sosial Pemugaran Rumah Tidak Layak Huni (RTLH) bagi penduduk miskin. Program tersebut salah satunya dilaksanakan di Desa Ngotet Kecamatan Rembang Kabupaten Rembang. Namun dalam pelaksanaanya, masih dinilai kurang tepat sasaran dikarenakan terdapat beberapa kriteria yang tidak dilaksanakan dalam menentukan masyarakat atau kelompok masyarakat yang berhak menerima bantuan sosial. Hasil penelitian menggunakan teori implementasi George C. Edwards III dengan fokus pada internal organisasi, terdapat beberapa indikator yang masih harus diperbaiki yaitu komunikasi yang berfokus pada konsistensi pelaksanaan; sumber daya baik dari sisi manusia dan anggaran; disposisi yaitu pengangkatan birokrasi dan insentif. Adapun yang sudah berjalan baik yaitu struktur birokrasi pada sisi mekanisme dan struktur birokrasi di Dinas Perumahan Dan Kawasan Permukiman Kabupaten Rembang.
\end{abstract}

Keywords: Kemiskinan, Implementasi Bantuan Sosial Pemugaran Rumah Tidak

\section{Layak Huni (RTLH)}

\section{PENDAHULUAN}

Kemiskinan diartikan sebagai kondisi ketidakmampuan pendapatan dalam mencukupi kebutuhan pokok sehingga kurang mampu untuk menjamin kelangsungan hidup (Suryawati, 2004: 122). Selanjutnya Suyanto (2013: 2) mengatakan kemiskinan

\footnotetext{
${ }_{1}^{1}$ Mahasiswa Prodi S2 IImu Administrasi, Departemen Adm Publik, Universitas Diponegoro

${ }^{2}$ Mahasiswa Prodi S2 IImu Administrasi, Departemen Adm Publik, Universitas Diponegoro

${ }^{3}$ Dosen Prodi S2 IImu Administrasi, Departemen Adm Publik, Universitas Diponegoro
} 
sesungguhnya bukan semata-mata kurangnya pendapatan untuk memenuhi kebutuhan pokoknya atau standar hidup layak.

Pada tahun 2017, Provinsi Jawa Tengah menempati posisi dua puluh satu dari tiga puluh empat provinsi dengan jumlah penduduk miskin tertinggi. Namun sampai dengan tahun 2017, kondisi Kemiskinan di Provinsi Jawa Tengah terus memperlihatkan perubahan yang positif, dimana selalu terjadi penurunan jumlah penduduk miskin sejak tahun 2011 sebanyak 5,317 juta jiwa atau sebesar 16,20\% terus menurun hingga tahun 2017 menjadi sebanyak 4,197 juta penduduk atau sebesar 12,23\%. Berikut data kemiskinan di Provinsi Jawa Tengah yang selengkapnya dapat dilihat pada gambar 1.1 dibawah ini :

\section{Kemiskinan Provinsi Jawa Tengah Kondisi Maret 2011 - September 2017}

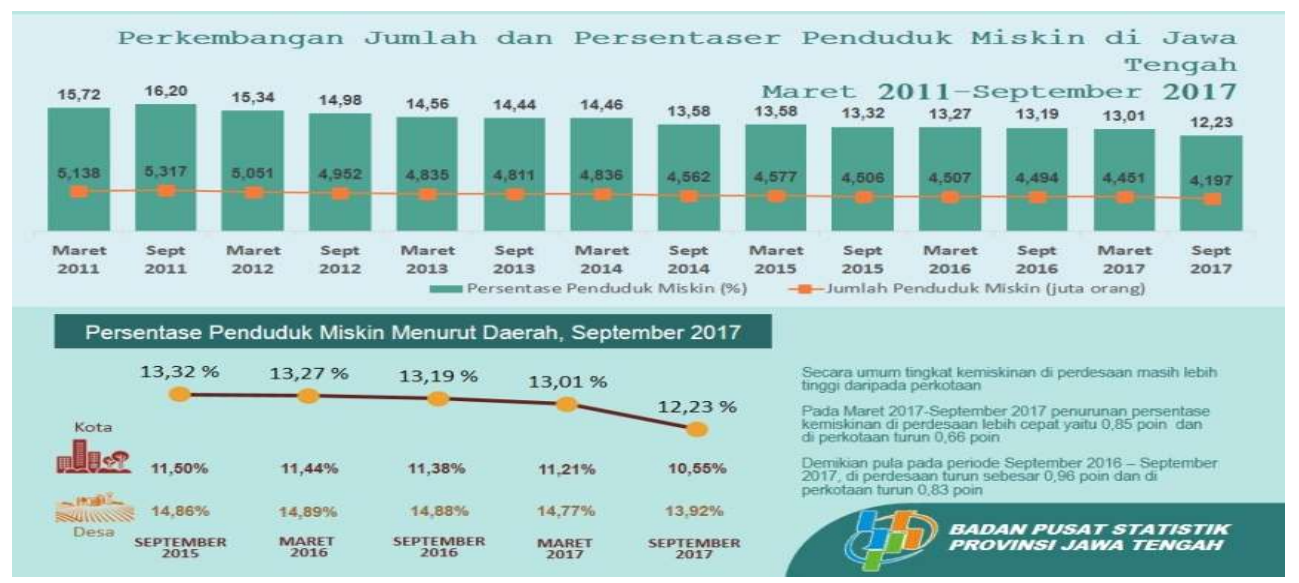

Sumber : Berita Resmi Statistik No. 05/01/33/Th. XXI, 2 Januari 2018

Angka kemiskinan yang relatif masih tinggi tersebut salah satunya dikarenakan kondisi Provinsi Jawa Tengah yang sebesar 42,85\% atau dari tiga puluh lima kabupaten/kota yang ada di Provinsi Jawa Tengah terdapat lima belas kabupaten yang masuk dalam wilayah zona merah atau daerah miskin. Salah satunya yang tertinggi adalah Kabupaten Rembang yang pada tahun 2002, persentase penduduk miskin sebesar 33,38\% dan sampai dengan tahun 2017 menjadi sebesar 18,35\% sehingga terjadi penurunan persentase penduduk miskin di Kabupaten Rembang sebesar 15,03\%. Adapun data selengkapnya dapat dilihat pada gambar 1.2 di bawah ini : 


\section{Perkembangan Kemiskinan Kabupaten Rembang Tahun 2002-2017}

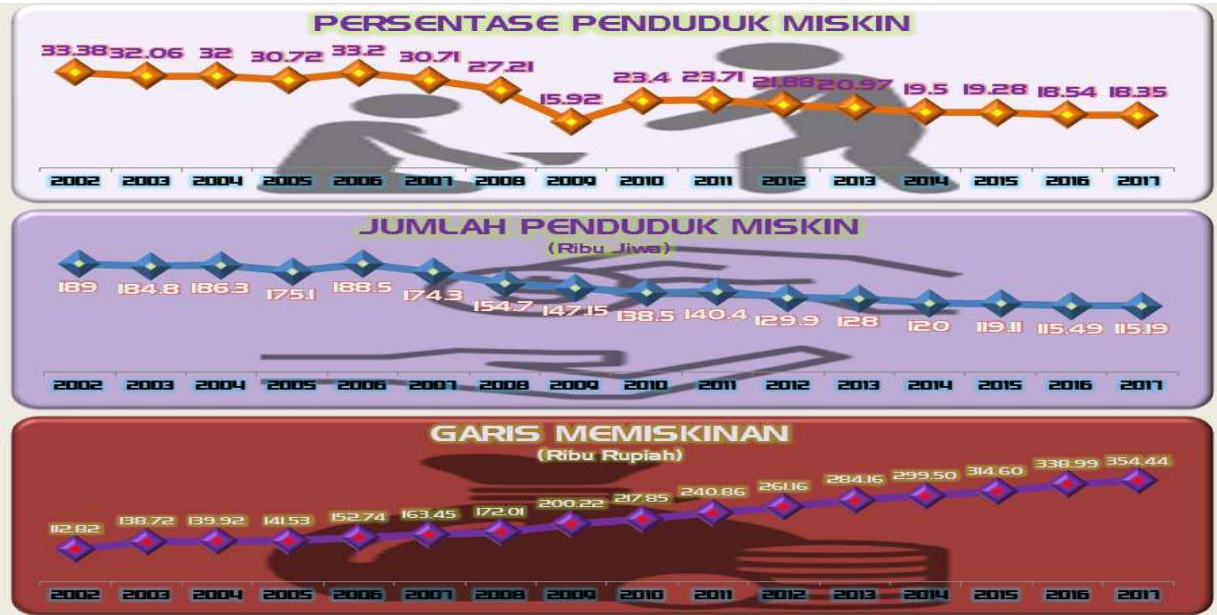

Sumber : rembangkab.bps.go.id

Tingginya persentase penduduk miskin yang ada di Kabupaten Rembang tersebut mencerminkan masih banyaknya rumah penduduk yang masuk dalam kategori tidak layak huni. Oleh sebab itu, Pemerintah Kabupaten Rembang pada tahun 2017 mulai melaksanakan Program Bantuan Sosial Pemugaran Rumah Tidak Layak Huni (RTLH) bagi penduduk miskin melalui Keputusan Kepala Dinas Perumahan dan Kawasan Permukiman Kabupaten Rembang Nomor 640/159 Tahun 2017 tentang Petunjuk Teknis Pelaksanaan Bantuan Sosial Pemugaran Rumah Tidak Layak Huni (RTLH) Tahun Anggaran 2017.

Namun dalam pelaksanaannya, program bantuan sosial pemugaran rumah tidak layak huni (RTLH) masih belum sesuai harapan. Kondisi ini karena beberapa kriteria masyarakat yang berhak menerima bantuan sosial tidak tepat sasaran, seperti yang terjadi di Desa Ngotet Kecamatan Rembang Kabupaten Rembang, dimana dari dua puluh pengajuan hanya sepuluh pengajuan yang memenuhi syarat meskipun dari sepulu pengajuan yang memenuhi syarat tersebut masih terdapat dua calon penerima bantuan sosial yang kurang tepat. Adapun data selengkapnya dapat dilihat pada tabel 1.1 dibawah ini : 
Tabel 1.1

Daftar pemohon bantuan sosial pemugaran rumah tidak layak huni di Desa Ngotet Tahun 2016

\begin{tabular}{|c|l|l|r|c|}
\hline No & $\begin{array}{l}\text { Nama Bakal Calon } \\
\text { Penerima Bantuan }\end{array}$ & Pekerjaan & \multicolumn{1}{c|}{ Penghasilan/Bulan } & $\begin{array}{c}\text { Penerima } \\
\text { Bantuan }\end{array}$ \\
\hline 1. & Taslan & Petani & $1.500 .000-1.700 .000$ & TMS \\
\hline 2. & Ainurohmah & Petani & $900.000-1.100 .000$ & TMS \\
\hline 3. & Amin Nur Rohman & Petani & $\mathbf{9 0 0 . 0 0 0}-\mathbf{1 . 1 0 0 . 0 0 0}$ & MS \\
\hline 4. & Iskandar & Buruh & $1.200 .000-1.400 .000$ & TMS \\
\hline $\mathbf{5 .}$ & Pardi & Buruh & $\mathbf{1 . 2 0 0 . 0 0 0}-\mathbf{1 . 4 0 0 . 0 0 0}$ & MS \\
\hline $\mathbf{6 .}$ & Ahmat Cholik & Buruh & $\mathbf{1 . 2 0 0 . 0 0 0}-\mathbf{1 . 4 0 0 . 0 0 0}$ & MS \\
\hline 7. & Sarno & Buruh & $\mathbf{9 0 0 . 0 0 0}-\mathbf{1 . 1 0 0 . 0 0 0}$ & MS \\
\hline $\mathbf{8 .}$ & Supriyadi & Nelayan & $\mathbf{1 . 5 0 0 . 0 0 0}-\mathbf{1 . 7 0 0 . 0 0 0}$ & MS \\
\hline 9. & Ibrahim & Buruh & $1.200 .000-1.400 .000$ & TMS \\
\hline 10. & Azam & Nelayan & $1.200 .000-1.400 .000$ & TMS \\
\hline 11. & Tifah & Buruh & $900.000-1.100 .000$ & TMS \\
\hline 12. & Rasmi & Petani & $\mathbf{1 . 2 0 0 . 0 0 0}-\mathbf{1 . 4 0 0 . 0 0 0}$ & MS \\
\hline $\mathbf{1 3 .}$ & Puji Lestari & Petani & $\mathbf{9 0 0 . 0 0 0}-\mathbf{1 . 1 0 0 . 0 0 0}$ & MS \\
\hline 14. & Musa & Buruh & $900.000-1.100 .000$ & TMS \\
\hline 15. & Zainal Abidin & Buruh & $900.000-1.100 .000$ & TMS \\
\hline $\mathbf{1 6 .}$ & Sariman & Nelayan & $\mathbf{9 0 0 . 0 0 0}-\mathbf{1 . 1 0 0 . 0 0 0}$ & MS \\
\hline 17. & Mukti & Petani & $1.200 .000-1.400 .000$ & TMS \\
\hline 18. & Adi & Petani & $1.200 .000-1.400 .000$ & TMS \\
\hline $\mathbf{1 9 .}$ & Tasmi & Buruh & $\mathbf{9 0 0 . 0 0 0}-\mathbf{1 . 1 0 0 . 0 0 0}$ & MS \\
\hline $\mathbf{2 0 .}$ & Salamin & $\mathbf{9 0 0 . 0 0 0}-\mathbf{1 . 1 0 0 . 0 0 0}$ & MS \\
\hline
\end{tabular}

Sumber : Dinas Perumahan dan Kawasan Permukiman Kabupaten Rembang 2017

Dari data di atas dapat dilihat calon penerima bantuan sosial pemugaran rumah tidak layak huni pada tahun 2016 yang diajukan ke Dinas Perumahan dan Kawasan Permukiman Kabupaten Rembang berdasarkan rekomendasi dari Kepala Desa Ngotet. Namun berbeda dari data yang diperoleh dari Dinas Perumahan dan Kawasan Permukiman Kabupaten Rembang bahwa nama-nama yang diajukan sebanyak 20 orang hanya 10 orang yang mendapatkan bantuan pemugaran rumah tidak layak huni. Dapat 
dilihat juga bahwa terdapat masyarakat yang berpenghasilan antara rentang 1,5 juta $-1,7$ juta rupiah mendapatkan bantuan hibah, padahal dalam pengajuan terdapat masyarakan berpenghasilan 900 ribu - 1,1 juta tidak mendapatkan bantuan.

Dari penjabaran permasalahan diatas masih terdapat kriteria pemberian bantuan sosial pemugaran rumah tidak layak huni yang tidak sesuai, oleh sebab itu penulis mengangkat penelitian dengan judul "Implementasi Program Bantuan Sosial Pemugaran Rumah Tidak Layak Huni (RTLH) Di Desa Ngotet Kabupaten Rembang Tahun 2017”.

\section{Tujuan}

1. Untuk mengetahui bagaimana proses pelaksanaan bantuan sosial pemugaran rumah tidak layak huni di Desa Ngotet.

2. Untuk mengetahui hambatan apa saja yang dihadapi selama pelaksanaan bantuan sosial pemugaran rumah tidak layak huni di Desa Ngotet.

\section{Tinjauan Pustaka}

Model implementasi kebijakan yang digunakan dalam penelitian ini adalah model implementasi dari George C. Edwards III. Model tersebut dipilih karena bantuan sosial pemugaran rumah bukan bersifat pemberdayaan yang membutuhkan penyuluhan atau pendampingan secara berkala melainkan hanya pemberian uang untuk pemugaran rumah tidak layak huni. Adapun variabelnya adalah :

1. Komunikasi (Transmisi, Kejelasan dan Konsistensi);

2. Sumber Daya (Sumber Daya Manusia, Anggaran, Fasilitas, Informasi Dan Kewenangan);

3. Disposisi (Pengangkatan Birokrasi dan Insentif);

4. $\quad$ Struktur Birokrasi (Mekanisme dan Struktur Birokrasi);

Metode Penelitian

Penelitian ini menggunakan jenis penelitian deskriptif kualitatif, yaitu jenis penelitian yang digunakan untuk meneliti pada kondisi objek yang alamiah dengan membuat deskripsi atau lukisan secara sisematis dan akurat mengenai fakta, sifat, serta hubungan antara fenomena yang sedang diselidiki dan menjelaskan fenomena-fenomena yang terjadi yang berkaitan dengan penelitian yang di teliti (Moleong, 2012:6). Fokus dari penelitian ini adalah proses implementasi program bantuan sosial pemugaran rumah tidak layak huni. Lokus utama penelitian dilaksanakan di Desa Ngotet Kecamatan Rembang Kabupaten Rembang yang merupakan salah satu dari sekian Desa yang 
mendapat bantuan sosial pemugaran rumah tidak layak huni dimana di daerah tersebut ditemukan adanya sasaran bantuan yang tidak tepat bagi masyarakat miskin sehingga tidak bisa melanjutkan pembangunan rumahnya. Selanjutnya menurut Lofland dalam Moleong (2012:157) sumber data utama dalam penelitian kualitatif ialah kata-kata, dan tindakan, selebihnya adalah data tambahan seperti dokumen. Berkaitan dengan itu maka jenis data yang terdapat dalam penelitian ini adalah data primer dan sekunder yang diambil meliputi katakata dan tindakan; sumber tertulis; dan foto. Dalam melakukan pemilihan informan untuk mendukung hasil penelitian, maka pemilihan key informan dilakukan dengan teknik purposive yaitu memilih orang yang benar-benar mengetahui dan menguasai serta terlibat langsung dengan permasalahan yang sedang diteliti. Informan adalah orang yang memberi informasi tentang data yang diinginkan peneliti berkaitan dengan penelitian yang sedang dilaksanakannya. (Idrus, 2009: 91). Key informan dalam penelitian ini adalah Kepala Dinas Perumahan dan Kawasan Permukiman Kabupaten Rembang; Kepala Seksi Perumahan; dan masyarakat desa Ngotet.

Informan lain akan ditentukan dengan menggunakan teknik snowball. Teknik pengumpulan data yang digunakan adalah wawancara, observasi dan studi dokumentasi. Data yang diperoleh dari informan selanjutnya akan dianalisis secara sistematis dengan melakukan tiga langkah secara bersamaan yaitu reduksi data, penyajian dan penarikan kesimpulan/verifikasi.

\section{PEMBAHASAN}

Dalam model implementasi George C. Edwards III, variabel yang pertama adalah komunikasi. Komunikasi berkenaan dengan bagaimana kebijakan dikomunikasikan kepada organisasi dan/ atau publik dan sikap serta tanggapan dari para pihak yang terlibat. Terdapat tiga indikator yang dapat dipakai dalam mengatur keberhasilan variabel komunikasi yaitu Transmisi, dari hasil penelitian ditemukan bahwa penyaluran komunikasi yang disampaikan oleh pimpinan kepada staf sudah berjalan dengan baik, dimana pimpinan selalu mengadakan rapat internal dalam pembahasan mekanisme pemberian bantuan sosial pemugaran rumah tidak layak huni (RTLH); indikator kedua yaitu kejelasan, dari hasil penelitian ditemukan bahwa Kejelasan arahan yang disampaikan oleh pimpinan sampai kepada staf sudah tercermin dalam pelaksanaan rapat internal dalam pembahasan mekanisme pemberian bantuan sosial pemugaran rumah tidak 
layak huni dan penyusunan petunjuk teknis pemberian program bantuan sosial namun masih terdapat kriteria yang belum tegas seperti kriteria masyarakat berpenghasilan rendah; indikator terakhir dalam variabel komunikasi adalah konsistensi, dari hasil penelitian ditemukan bahwa indikator ini menjadi bagian yang perlu ditingkatkan karena pelaksanaan program bantuan sosial ini telah dilaksanakan mulai tahun 2012 dan telah beberapa kali mempunyai pengampu yang berbeda. Hal tersebut dikarenakan adanya penyesuaian nomenklatur organisasi perangkat daerah di Kabupaten Rembang. Pada tahun 2017 ini, untuk program bantuan sosial ini diampu oleh Dinas Perumahan Dan Kawasan Permukiman Kabupaten Rembang.

Variabel kedua yaitu Sumber Daya yang terdiri dari tiga indikator, yaitu Sumber Daya Manusia, pada indikator ini pegawai yang dimiliki oleh Dinas Perumahan Dan Kawasan Permukiman merupakan pegawai yang baru dan belum pernah mengampu kegiatan bantuan sosial tersebut. Adapun organisasi pengampu pada tahun 2016 sudah dilakukan restrukturisasi dan pegawai yang lama tidak menjadi bagian dalam tim verifikasi program bantuan sosial tersebut. Indikator kedua adalah anggaran. Salah satu yang menjadi penghambat adalah keterbatasan anggaran untuk melakukan verifikasi lapangan terhadap kondisi calon penerima bantuan sosial. Bantuan sosial yang masuk dalam kode rekening Organisasi perangka Daerah berbentuk 1 paket bantuan dengan masing-masing besaran adalah sepuluh juta rupiah tanpa disertai dengan dana pendukung untuk melakukan verifikasi lapangan. Yang ketiga yaitu fasilitas atau sarana prasarana yang sudah mendukung program bantuan sosial tersebut. Antara lain adanya komputer, printer dan alat elektronik maupun kendaaraan pendukung.

Variabel ketiga adalah disposisi yaitu watak dan karakteristik yang dimiliki oleh implementor seperti komitmen, kejujuran dan sifat demokratis. Hal-hal penting yang perlu dicermati pada variabel disposisi adalah Pengangkatan Birokrasi dimana masih perlu dilakukan bimbingan teknis mengenai tata cara pengelolaan program bantuan sosial pemugaran rumah tidak layak huni (RTLH) di Kabupaten Rembang. Hal tesebut dikarenakan pengampu program tersebut pada tahun 2017 sudah berbeda dengan pengampu pada tahun 2016. Selain itu adalah insentif yang dalam pelaksanaan program bantuan sosial pemugaran rumah tidak layak huni di Kabupaten Rembang, faktor insentif belum diperhatikan oleh pengambil kebijakan yang ada di Kabupaten Rembang. Hal ini 
dirasa perlu, sebagai salah satu pendorong keberhasilan karena besarnya beban dan tanggung jawab yang diemban dalam setiap proses bantuan sosial yang akan disalurkan.

Variabel keempat atau terakhir dalam model ini adalah struktur birokrasi dimana aspek struktur organisasi ini melingkupi dua hal yaitu mekanisme dan struktur birokrasi itu sendiri. Untuk mekanisme pelaksanaan bantuan sosial pemugaran rumah tidak layak huni prosesnya dimulai dengan pengajuan proposal kepada Sekretaris Daerah Kabupaten Rembang dengan tembusan Kepala Dinas Perumahan Dan Kawasan Permukiman Kabupaten Rembang sebagai pengampu. Syarat yang harus dipenuhi antara lain fotocopi KTP, surat keterangan penghasilan dan keterangan domisili dari desa serta dokumentasi rumah yang diusulkan bantuan. Proses birokrasi yang berjalan sudah tepat dan tidak terlalu panjang. Guna pedoman program bantuan sosial ini sebenarnya dalam pelaksanaan telah disusun peraturan Keputusan Kepala Dinas Perumahan dan Kawasan Permukiman Kabupaten Rembang Nomor 640/159 Tahun 2017 tentang Petunjuk Teknis Pelaksanaan Bantuan Sosial Pemugaran Rumah Tidak Layak Huni (RTLH) Tahun Anggaran 2017. Namun masih terdapat satu kriteria yang belum jelas dalam peraturan tersebut, salah satunya adalah penjelasan mengenai definisi masyarakat berpenghasilan rendah.

\section{PENUTUP}

\section{Kesimpulan}

Berdasarkan uraian di atas dapat ditarik kesimpulan bahwa belum maksimalnya pelaksanaan program bantuan sosial pemugaran rumah tidak layak huni di Kabupaten Rembang dikarenakan beberapa faktor yang masih harus ditingkatkan seperti :

1. Komunikasi, faktor yang menjadi penghambat adalah kejelasan dan konsistensi pelaksana.

2. Sumber Daya, faktor yang menjadi penghambat adalah sumber daya manusia dan anggaran pendukung pelaksanaan program bantuan sosial pemugaran

3. Disposisi, faktor yang menjadi penghambat adalah pengangkatan birokrasi dan insentif.

4. Struktur Birokrasi yang terdiri dari mekanisme dan struktur birokrasi ini sudah berjalan dengan baik karena sudah terdapat SOP dan kejelasan pola dalam pembagian tugas untuk pelaksanaan program bantuan sosial pemugaran rumah tidak layak huni di kabupaten rembang. 


\section{Rekomendasi}

Berdasarkan hasil penelitian di atas maka rekomendasi penulis antara lain :

1. Diperlukan dana pendukung lain dalam pelaksanaan program bantuan sosial pemugaran rumah tidak layak huni, seperti anggaran monitoring dan evaluasi program dan anggaran bimbingan teknis pengelolaan bantuan sosial bagi staf pengampu guna peningkatan kapasitas pegawai.

2. Menyusun regulasi yang lebih jelas pada setiap kriteria permohonan bantuan sosial pemugaran rumah tidak layak huni agar tidak terjadi salah penafsiran oleh setiap individu yang membaca.

\section{DAFTAR PUSTAKA}

Ibrahim, Amin. 2009. Pokok-Pokok Administrasi Publik dan Implementasinya. Bandung : Refika Aditama.

Idrus, Muhammad, 2009. Metode Penelitian Ilmu Sosial. Jakarta: Erlangga.

Moleong, Lexy, J. 2012. Metodologi Penelitian Kualitatif. Bandung: PT. Remaja Rosda Karya.

Nugroho, Riant. 2014. Publik Policy Teori, Manajemen, Dinamika, Analisis, Konvergensi, dan Kimia Kebijakan Edisi 5. Jakarta : Elex Media Komputindo.

Pasolong, Harbani, 2008. Teori Administrasi Publik, Bandung : Alfabeta.

Suyanto, Bagoang, 2013. Anatomi Kemiskinan dan strategi penanganannya, Malang: InTRANS Publishing

Yeremias T Keban. 2014. Enam Dimensi Strategis Administrasi Publik. Yogyakarta: Gava Media

Keputusan Kepala Dinas Perumahan dan Kawasan Permukiman Kabupaten Rembang Nomor 640/159 Tahun 2017 tentang Petunjuk Teknis Pelaksanaan Bantuan Sosial Pemugaran Rumah Tidak Layak Huni (RTLH) Tahun Anggaran 2017. http://e-journal.uajy.ac.id/1756/3/2EP15294.pdf diakses pada tanggal 2 Oktober 2018 pukul 14:24 WIB.

https://www.bps.go.id/pressrelease/2018/07/16/1483/persentase-penduduk-miskinmaret-2018-turun-menjadi-9-82-persen.html diakses pada tanggal 2 Oktober 2018 pukul 15:03 WIB 
https://jateng.bps.go.id/pressrelease/2018/07/16/1020/persentase-penduduk-miskinmaret-2018-sebesar-11-32-persen.html diakses pada tanggal 2 Oktober 2018 pukul 15:06 WIB 